\title{
“But, don't you think...?”: chat educacional na formação inicial de professores de inglês para a reflexão ${ }^{1}$
}

\author{
Lucas Moreira dos Anjos-Santos \\ Monash University, Melbourne, Austrália/CAPES \\ lmanjos.santos@gmail.com \\ Eliane Segati Rios-Registro \\ Universidade Estadual do Norte do Paraná (UENP) \\ Campus Cornélio Procópio \\ eliane_segati@uenp.edu.br
}

\section{Resumo}

Esse artigo objetiva investigar a atividade de participação de alunosprofessores em um chat educacional e as reflexões propiciadas ou não por meio do uso desse gênero digital. Partimos do pressuposto de que a atividade de reflexão situada pode ser uma das ferramentas para formação de professores comprometidos com suas práticas e capazes de orientar e tomar decisões com bases em seus contextos de atuação. Os dados analisados são de uma pesquisa conjunta desenvolvida por pesquisadores de duas universidades estaduais do norte do Paraná. Os participantes da pesquisa são alunosprofessores dos terceiro e primeiro anos do curso de Letras-Inglês. Os resultados demonstram que o uso do chat educacional pode ser adequado a situações em que o aluno-professor tenha sua voz ouvida e quebre padrões de assimetria entre professor e aluno-professor.

Palavras-chave: chat educacional; formação inicial de professores de inglês; atividade de reflexão

${ }^{1}$ Artigo fruto das discussões e reflexões realizadas na disciplina Modelos $e$ Práticas Reflexivas na Formação do Professor de Língua Estrangeira, ministrada pela professora Dra. Telma Gimenez, no Programa de PósGraduação em Estudos da Linguagem da Universidade Estadual de Londrina. 


\section{Abstract}

This article aims to investigate the participation of pre-service teachers in an educational chat and the reflection promoted or not by the use of this digital genre.The investigation is based on the assumption that the activity of situated reflection can be one of the tools for educating teachers committed to their practices and capable of making decisions by assessing their professional contexts. The data analyzed are part of a joint research developed by researchers from two state universities in the north of Paraná. The research participants are pre-service teachers from third and first years in an English Language undergraduate degree. The results show that the use of educational chats can be adequate to situations in which pre-service teachers have their voices heard and break asymmetry patterns between teacher educators and pre-service teachers

Keywords: educational chat; pre-service English teacher education; situated reflection

\section{Considerações iniciais}

A formação de um profissional da linguagem, assim como quaisquer profissionais, se dá por meio do engajamento deste em comunidades discursivas pouco familiares a priori ao mesmo tempo em que transforma e consolida novos repertórios comunicacionais necessários à participação nessas comunidades (MATÊNCIO, 2008; LAVE; WENGER, 1991). Ao se engajar em práticas linguageiras da comunidade na qual pretende participar, o futuro profissional (re)constrói sua identidade enquanto membro de determinada esfera humana. $\mathrm{O}$ aprendizado de novas práticas linguageiras é acompanhado do aprendizado de novas formas de agir no mundo (BRONCKART, 2008; CRISTOVÃO, 2010).

No entanto, o processo de formação de professores de línguas é marcado por experiências anteriores como aprendizes de língua e do sistema escolar. Há, nesse sentido, uma confrontação entre representações e vivências previamente construídas com novas formas de ser e agir (GIMENEZ, 1998). O conceito de reflexão como atividade situada pode ser, portanto, uma das atitudes a ser desenvolvida, ao longo do processo de formação, para o alunoprofessor ser capaz de tomar decisões coerentes com o contexto no qual atuará e as práticas sociais de referência. 
Nesse artigo,temos por objetivo analisar a atividade de participação em um chat educacional e as reflexões propiciadas ou não por meio do uso desse instrumento. Os dados analisados são um recorte da pesquisa de mestrado de um dos autores,e tem como participantes alunos-professores dos terceiro e primeiro anos do curso de Letras-Inglês de duas universidades públicas do interior do Paraná.

Para atingirmos nosso objetivo, traçaremos, primeiramente, um panorama sobre reflexão na formação de professores abordando a reflexão como atividade situada; após, o chat educacional e formação de professores,a apresentação da metodologia, a análise de dados e, finalmente, as considerações finais.

\section{Panorama sobre reflexão na formação de professores}

A formação de professores tem sido permeada por discursos que ressaltam a necessidade de melhoria da prática profissional do professor, assim como das características mínimas que tal profissional precisaria reunir. Como bem aponta Gimenez (2005), a formação de professores é embasada por um processo de aprendizagem em que é levado em conta o que o aprendiz já sabe e é mediada por um par mais experiente, por um processo que permita a reflexão dos alunosprofessores para a tomada de decisão e, por fim, por um projeto político de transformação social.

Nesse contexto, os termos reflexão e professor reflexivo tornaram-se imbuídos de significações múltiplas com vistas a possibilitar um salto qualitativo no trabalho do professor (cf. MARQUES, 2004; FLENDER, 2003; CORACINI, 2003; PIMENTA, 2002; CONTRERAS, 2002; ZEICHNER, 1994). Levantamos sucintamente a seguir um panorama sobre reflexão na formação de professores para podermos situar a análise posterior adequadamente.

De acordo com Schön (1987), futuros profissionais aprendem ao se engajar em práticas da futura profissão. Para tanto, o autor defende uma formação baseada em coaching, na qual um par mais experiente poderia guiar o processo de reflexão de um par menos experiente. O autor consagrou os termos "reflexão na ação" e "sobre a ação" que incidem sobre processos de reorientação da prática por meio 
da análise das próprias práticas num movimento consciente, deliberado, individual e autorregulado.

Nesse sentido, a principal crítica a essa concepção de reflexão é que ela acaba por criar mecanismos de autorresponsabilização do professor pelas mazelas do ensino, como bem apontou Contreras (2002). Além do mais, tal concepção peca em apreender questões macroestruturais que incidem sobre o trabalho do professor. Deveríamos, então, abandonar a reflexão como um instrumento para formação de professores?

Diversos autores, entre eles Contreras (2002) e Pimenta (2002), fazem uma releitura do conceito de reflexão de modo a ampliar o escopo da análise que tal instrumento pode ter na formação de professores. Para Contreras (2002), é necessário levar em conta o poder exercido pelas instituições educativas na tomada de decisão do professor, assim como, práticas sociais, historicamente construídas e mantidas, na sociedade. Ou seja, “(...) teríamos que aceitar que a mera reflexão sobre o trabalho do professor em classe pode ser insuficiente para elaborar uma compreensão teórica sobre aqueles elementos que condicionam sua prática profissional, mas dos quais não pode ter consciência" (CONTRERAS, 2002, p.155).

Para tanto, Contreras, tendo por base Giroux (1997), defende que a reflexão para o professor deveria ser pautada em uma crítica a condições históricas dadas e pudesse permitir um olhar em perspectiva sobre o papel que o trabalho desse profissional pode desempenhar para a transformação de um mundo mais democrático, igualitário e justo.

$\mathrm{Na}$ mesma linha de pensamento, Pimenta (2002) elenca uma série de críticas ao conceito de reflexão conforme difundido na área educacional. A autora problematiza o uso do termo reflexão como ferramenta de suporte à lógica de mercado nas instituições de treinamento de professor e ao próprio pragmatismo e perigo em acentuar a prática como lócus essencial da formação do professor. Ambas as concepções são embasadas por uma prática neoliberal de privatização de serviços públicos e a serviço das hegemonias capitalistas. Dessa forma, a autora defende que é necessária a“(...) realização de uma articulação, no âmbito das investigações sobre prática docente reflexiva, entre práticas cotidianas e contextos mais amplos, considerando o ensino como prática social concreta" (PIMENTA, 2002, p. 24). 
Uma vez problematizado o conceito de reflexão, a autora defende que o conceito incorpore o papel da teoria e o abandono do individualismo rumo à coletividade para incorporar situações de formação mais condizentes com as necessidades do mundo no qual vivemos.

Ora, poderíamos, então, pensar no ensino reflexivo e na formação para reflexão como processos importantes à formação de professores? Acreditamos, pois, que o avanço no conceito de reflexão propiciou novos olhares sobre questões micro e macro contextuais que incidem sobre a educação. Porém, ainda sentimos a necessidade de ampliar um pouco mais esse conceito para abarcar o papel da linguagem e de práticas de engajamento social no processo de formação. Dessa forma, discutiremos,no tópico a seguir, o conceito de reflexão como atividade situada.

\subsection{Reflexão como atividade situada}

Após a breve explanação sobre o panorama da reflexão na formação de professores, abordaremos a reflexão como atividade situada. Para tanto, é necessário começarmos pelo contexto mais amplo do qual emerge essa conceituação, isto é, pelas comunidades de prática.

Formada por pessoas que compartilham interesses em comum e que buscam um aprendizado coletivo em contextos compartilhados, as comunidades de práticapodem possibilitar que a aprendizagem situada ocorra. Entretanto, para identificarmos uma comunidade como de prática e distingui-la de outros grupos e comunidades, devemos considerar três características tidas como fundamentais para o seu reconhecimento (WENGER, 1998): o domínio, a comunidade e a prática.

O primeiro, o domínio, considera que a comunidade de prática deva ter uma identidade definida por um domínio compartilhado de interesses diferenciando os seus integrantes de outros grupos. $\mathrm{O}$ segundo, a comunidade, considera o alto nível de engajamento de seus integrantes por meio de um relacionamento de confiança, compartilhando informações e conhecimentos, interagindo uns com os outros.Por último, é necessário considerara prática. Os membros desta 
comunidade são praticantes e desenvolvem um repertório compartilhado de recursos como experiências, instrumentos, entre outros.

Com isso, Wenger (1998) sustenta que é justamente na combinação dos três elementos acima citados que uma comunidade de prática constitui-se, podendo também ser conhecida como grupos temáticos, redes de aprendizagem, a partir da linha teórica assumida.

Para o autor supracitado, aprendizagem envolve a participação em uma comunidade de prática. Muito mais do que uma participação em eventos locais com determinadas pessoas, a aprendizagem é gerada por meio de participação ativa nas práticas de comunidades sociais, construindo identidades em relação a essas comunidades.

$\mathrm{O}$ conceito de comunidade de prática vem sendo aplicado em vários setores, a exemplo dos negócios, educação, governo, vida cívica, e muitos outros. O que nos interessa nesse momento é o setor educacional, mais precisamente a formação de professores de língua inglesa.

Levando em consideração a esfera educacional, Wenger (1998)afirma que a comunidade de prática perpassa por três dimensões, sendo: internamente, externamente e ao longo da vida acadêmica dos alunos. Com isso, ressaltamos que a escola não é o único espaço propulsor da aprendizagem, mas toda a experiência de vida que constitui o indivíduo. Portanto, a escola deve estar a serviço da aprendizagem que ocorre no mundo, e não em um contexto isolado.

Além do espaço educacional, destacamos o espaço virtual, mais especificamente a web. Nele, novas tecnologias, como a internet, avançam os limites das paredes de uma sala de aula para se conectarem ao mundo. Este espaço expande novas possibilidades de comunidades baseadas em uma prática compartilhada de aprendizagem, a exemplo do chat educacional sobre o qual discorreremos mais adiante.

Considerando a comunidade de prática uma atividade socialmente situada, percebemos o papel mediador que o contexto exerce não somente no aprendizado, mas também na identidade e consciência humana (OVENS; TINNING, 2009). Dessa forma, se consideramos que a reflexão pode ser mediada pelo contexto no qual o indivíduo faz parte, devemos problematizar se a natureza desta reflexão é influenciada pelas diferentes situações que o futuro professor pode encontrar em seu caminho de se tornar professor. 
Portanto, é no ínterim da subjetividade e do contexto social que Ovens e Tinning (2009) enfatizam que o conceito "situado" é de grande interesse para o estudo da reflexão. O mencionado campo de pesquisa provém de áreas distintas como da ciência cognitiva, da antropologia e da sociologia. Partindo dessa perspectiva, os autores afirmam que a reflexão pode ser sempre considerada como situada, uma vez que está inserida em um contexto social que faz uso de instrumentos conceituais presentes no contexto.

Além disso, Ovens e Tinning (2009) concordam com Lave e Wenger (1991) ao afirmarem que não há atividade que não seja socialmente situada e ressaltam que, dentre outros conceitos utilizados, assumem a expressão "comunidade discursiva" de forma a aproximar a natureza contextualizada da prática reflexiva e o papel que as pessoas desempenham ao criar esse contexto.

Dessa forma, as práticas coletivas de um grupo acabam por fornecer instrumentos cognitivos como teorias, ideias, conceitos, dos quais os indivíduos daquele grupo se apropriam para guiar e dar sentido às suas ações. Da mesma forma que os autores consideram o departamento de educação como uma comunidade discursiva, reconhecemos o curso de Letras como tal, uma vez que este representa uma coletividade que possui muitos interesses em comum.

Entretanto, devemos ter em mente a dualidade desse processo, pois apesar de uma comunidade poder ser aquela que representa uma coletividade, por meio de suas práticas e normas culturais, é o indivíduo quem monitora de forma reflexiva suas práticas individuais. Além disso, Ovens e Tinning (2009) consideram que é necessário levar em consideração que, em um contexto formado por futuros professores, estes frequentemente se adaptam ao contexto social no qual estão inseridos por meio da leitura de mundo que fazem dele,e que, por conseguinte, agem de acordo com o que lhes é esperado.

Portanto, corroboramos com os autores ao asseverarem que devemos dar uma atenção especial à compreensão das comunidades discursivas que são partes da educação de professores. Além disso, devemos atentar ao modo como os futuros professores negociam em tais comunidades ao longo do seu processo de aprendizagem.

Com isso, Ovens e Tinning (2009) sugerem que a reflexão precisa ser vista como uma atividade situada, capacitada pela 


\section{“But, don't you think...?”: chat educacional...}

participação dos alunos em contextos discursivos particulares. Por fim, que os limites da reflexão da natureza situada possam ser reconhecidos em relação às expectativas dos programas de formação de professores de modo que estes se tornem participantes reflexivos.

A seguir, trataremos de uma comunidade discursiva inserida no chat educacional em um programa de formação de professores.

\section{Chat educacional: instrumento para formação de professores?}

O chat é uma tecnologia digital que não requer instalação de nenhum programa de software para ser utilizado. Suas características incluem o uso de recursos audiovisuais e simulam uma conversa face a face. A interação que ocorre no chat é sincrônica. Os participantes entram em salas virtuais de chat de acordo com categorias préestabelecidas, como por exemplo, idade, sexo, cidade, preferência sexual, entre outros (ARAÚJO, 2004).

No entanto, dentre os diversos tipos de chat, fizemos uso, nesse trabalho, do chat educacional. Segundo Marcuschi (2004, p. 54) “(u)ma diferença básica do gênero chat educacional na relação com os bate-papos em salas abertas é o fato de os participantes se conhecerem ou serem identificados por seus nomes e a entrada ser limitada aos alunos". Ainda nesse sentido, Geraldini (2005) salienta as características do chat educacional como simulador de uma conversa face a face em função dos padrões interacionais mobilizados nessa prática discursiva.

A autora ressalta, no entanto, com base em Hilgert (2000), que a interação no chat educacional vai apresentar características próprias em função da centralidade da escrita nesse gênero, assim como as condições de produção do meio digital. Ao analisar chats educacionais, Geraldini (2005) entende que estes podem ser ferramentas que promovam aprendizagem conjunta ao reunir elementos de ordem cognitiva e afetiva dos seus participantes.

Analogamente, Leal (2007) analisou o papel da mediação para o desempenho da interação nesse contexto digital. Segundo a autora, o papel do professor enquanto mediador é essencial para garantir a função social do gênero chat educacional. No entanto, como bem aponta a autora,"o bate papo traz contribuições para o professor e para os alunos quando seu uso é planejado e efetivamente 'desejado', ou 
seja, há uma necessidade de usá-lo com algum objetivo pedagógico (...)" (LEAL, 2007, p. 60).

Uma das principais características levantadas pela autora diz respeito à quebra de hierarquia que o contexto de produção do chat educacional permite. $\mathrm{O}$ poder do professor pode ser atenuado em relação a quem gera a interação, e pode ampliar as possibilidades de participação dos alunos.

Dadas essas características elencadas com base na literatura existente, qual poderia, então, ser o papel dos chats educacionais como ferramentas para deflagrar momentos reflexivos na formação de professores? Partindo do pressuposto de Vygostky (1998) deque um instrumento, ao ser apropriado pelo e para o indivíduo, pode transformar a atividade na qual este se insere assim como o próprio sujeito, partimos da premissa de que o uso do gênero digital chat educacional pode promover desestabilizações em representações cristalizadas dos professores e permitir uma reconfiguração das mesmas (BRONCKART, 2006).

Com base nisso, passaremos, a seguir,a analisar interações em chat educacionais para identificar se momentos de reflexão emergem da situação analisada a partir do arcabouço teórico mobilizado sobre reflexão como atividade situada.

\section{Dados da pesquisa e dos participantes envolvidos}

Os dados analisados nesse trabalho são provenientes de uma pesquisa conjunta realizada pelos autores do artigo. Foram coletados na disciplina optativa "Gêneros textuais e ensino de línguas estrangeiras", como parte da pesquisa de mestrado de um dos autores, em duas universidades estaduais de cidades distintas do interior do estado do Paraná (U1 e U2) nos meses de setembro e outubro de 2010.

Os alunos-professores das respectivas universidades se engajaram na aprendizagem do gênero digital chat educacional como sendo uma das propostas da referida disciplina. Os alunos-professores da U1(A1;A2;A3; A4) estiveram em contato por cinco semanas com os alunos-professores da U2 (A1; A2; A3). Em cada encontro dispunham de um tópico, gerado a partir de um texto ou vídeo, para discussão que era mediado pelos professores (P1; P2). Além disso, 
havia um número variado de participantes em cada chat em função de problemas técnicos. No entanto, os participantes de pesquisa escolhidos estiverem presentes em todos os encontros.

De modo a contemplar o escopo deste artigo, focalizaremos nossa análise em dois momentos distintos da participação dos alunosprofessores em chats educacionais:o primeiro, ainda sem experiência com a tecnologia digital em questão e pouco familiarizados com esse contexto de produção e, o último, após intervenções para apreensão do gênero. Almejamos, dessa forma, identificar o papel dos chats educacionais no engajamento de um processo reflexivo, levando em consideração todo o arcabouço teórico aqui ressaltado.

\subsection{Procedimentos de análise dos dados}

Para análise dos chats, primeiramente, levantamos informações referentes ao contexto de produção da interação. A seguir, descrevemos o plano textual global ${ }^{2}$ (cf. BRONCKART,2003)das interações que foram selecionadas, para, por fim, identificarmos momentos de reflexão por meio da análise da linguagem utilizada pelos alunos-professores.

Os encontros para promoção das interações foram divididos em cinco momentos. No primeiro, houve o reconhecimento e apresentação dos integrantes dessa pesquisa por meio do Gmail bate papo, uma vez que uma das universidades, a U2, não possuía acesso livre em sua rede para o uso do Windows Live Messenger. No segundo encontro, de posse dessa liberação, pudemos interagir utilizando o Messenger. No terceiro, quarto e quinto encontros, a plataforma Moodle estava pronta e preparada para que nossos alunos-professores pudessem participar, conforme demonstramos na tabela 1 .

$\mathrm{O}$ número de participantes mudava de acordo com as possibilidades encontradas em cada dia. Deparamos, muitas vezes, com máquinas que não conseguiam acesso à rede de internet, além de falta de suporte de rede necessário para que houvesse esse tipo de

2 Plano textual global "refere-se à organização de conjunto do conteúdo temático; mostra-se visível no processo de leitura e pode ser codificado em um resumo" (BRONCKART, 2003, p.120). 
interação. Com isso, em alguns encontros dois alunos utilizavam a mesma máquina, o que justifica a variação no número de participantes.

Tabela 1: Quadro geral dos chat educacionais ocorridos

\begin{tabular}{|c|c|c|c|}
\hline Data & Tópico & $\begin{array}{c}\mathbf{N}^{\mathbf{0}} \text { de } \\
\text { particip }\end{array}$ & $\begin{array}{c}\text { Tipo de } \\
\text { software }\end{array}$ \\
\hline $15 / 09 / 2010$ & $\begin{array}{l}\text { Educação para todos } \\
\text { Educação e novas tecnologias }\end{array}$ & 7 & $\begin{array}{l}\text { Gmail Bate } \\
\text { Papo }\end{array}$ \\
\hline $22 / 09 / 2010$ & $\begin{array}{l}\text { Ensino de língua inglesa e } \\
\text { educadores globais }\end{array}$ & 6 & $\begin{array}{l}\text { Windows } \\
\text { Live } \\
\text { Messenger }\end{array}$ \\
\hline 29/09/2010 & $\begin{array}{l}\text { Papeis e representações sobre } \\
\text { trabalho docente }\end{array}$ & 8 & $\begin{array}{l}\text { Plataforma } \\
\text { Moodle }\end{array}$ \\
\hline $06 / 10 / 2010$ & $\begin{array}{l}\text { Ensino de língua inglesa e } \\
\text { transformação }\end{array}$ & 6 & $\begin{array}{l}\text { Plataforma } \\
\text { Moodle }\end{array}$ \\
\hline 20/10/2010 & $\begin{array}{l}\text { Ensino de língua inglesa e } \\
\text { novas tecnologias }\end{array}$ & 8 & $\begin{array}{l}\text { Plataforma } \\
\text { Moodle }\end{array}$ \\
\hline
\end{tabular}

\section{Análise das interações no chat educacional 1}

A primeira interação via chat contou com a participação de seis alunos-professores, sendo três alunos da U1 e três alunos da U2. O número total de interações de cada aluno está representado na Figura 1:

\section{INTERAÇÕES}

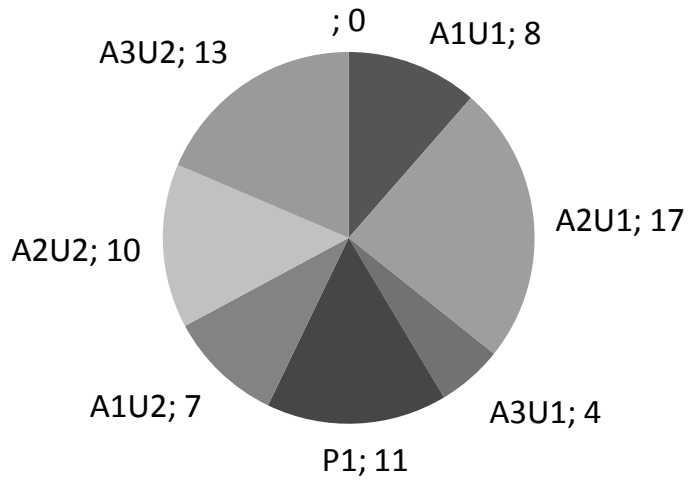

Figura 1 - Número de interações do primeiro chat educacional 
“But, don't you think...?”: chat educacional...

Os alunos da U1 se sobressaíram no número total de interações. Apesar da barreira linguística, tendo em vista que as interações foram feitas na língua inglesa, os alunos pareciam motivados a discutir e refletir acerca de assuntos referentes ao futuro de sua profissão.

A discussão desse chat estava ancorada em duas campanhas assistidas via You Tube pelos alunos-professores. Conforme ilustra o excerto 1, os alunos-professores enfocaram os papéis da sociedade na transformação da educação.

\section{Excerto 1}

A1U1: that video represents everything I have been saying throughout the years...we can change the world through education...but we have to do it and accept that it is our job to do it!!

A3U2: I agree. we find a lot of solutions for another problems, but for important things, we just hope that someday things get better

A2U1: right the video brings all the things we need for a transformation

P2: gevernmento, sorry

A2U1: we need money

A1P2: the power the comunication is strong, but need suport the idea A2U1: we need political will, as Eliane said ${ }^{3}$

Como podemos perceber, apesar do ideal de educação como transformação ser compartilhada pelos alunos-professores, de certa forma ecoando outros discursos amplamente debatidos na academia, a interação via chat lhes possibilitou uma co-construção de conhecimento sobre qual seria o papel da educação. Ainda é importante ressaltar, o papel do chat como instrumento para implicação dos alunos-professores ao opinarem, por meio do uso dos pronomes pessoais $I$ e we. Tal aspecto se torna importante, uma vez

${ }^{3}$ Reproduzimos nesse artigo as interações do chat educacional sem realizar qualquer alteração linguística. Apesar de haver colocações em dissonância da norma padrão da língua inglesa, tal característica não afetou a comunicação dos alunos-professores. Além do mais, é comum haver inadequações de ortografia e de concordância no gênero chat educacional em função da sua natureza síncrona e imediata. Uma discussão da aprendizagem de capacidades de linguagem desses alunos-professores se fará num outro momento. 
que essa ferramenta pode ser mola propulsora para que os alunosprofessores tenham suas vozes realmente expressadas e capazes de serem ouvidas.

Ambas as questões levantadas podem ser indícios de atitudes reflexivas desses profissionais em formação, já que se veem implicados na esfera profissional da qual participam. Mais do que criticar um estado de coisas, os alunos-professores se sentem na responsabilidade de mudar um estado de coisas. É uma atitude reflexiva a favor da transformação social conforme amplamente defendido por Contreras (2002) e Giroux (1997).

$\mathrm{O}$ excerto a seguir ilustra um momento de negociação de sentidos acerca de quem deve se responsabilizar pela melhoria na educação. A2U1 indaga quem seria "everybody" que é responsável pela qualidade da educação. A partir dessa sentença interrogativa,a discussão desenrola-se.

\section{Excerto 2}

A2U1: but who is this "everybody"?

A2U2: we needs many things to get there, we can't desmotivated eu: people, too

A2U1: teachers, students, governments, family.... society as a whole $[\ldots]$

A2U1: we can't get desmotivated that's true otherwise, nothing will happen A1U2: the money is the problem, the teacher is solution

A3U2: everyone has the power to change, including with the voto A2U1: rsrs, you're correct, A3U2 but unfortunately the voto is what desmotivates me most

A1U1: Come on...it is 5 million children...how can we change this sceneif people don't do anything..that is what the video is trying to show...the crasiest idea can became the better ones...we must keep on the hard work!!!

Os alunos-professores, no excerto 2, articulam o papel da sociedade civil no exercício político para transformação social. Este tema é trazido por A3U2 e problematizado por A2U1. Na sequência, A1U1 sintetiza aquilo que acredita ser realmente relevante nesse processo. A pouca assimetria existente entre os alunos-professores, por ocuparem posição social parecida, parece favorecer ao questionamento e engajamento na solução dos problemas por eles mesmos 


\section{“But, don't you think...?”: chat educacional...}

apresentados. No entanto, ressaltamos que tal característica, a de atenuação da assimetria, não é automaticamente garantida pelo uso chat educacional em si. As condições que o professor mediador cria para que os alunos-professores possam se arriscar e assumir papéis sociais menos hierarquizados são essenciais.

Diante dos excertos apresentados, parece haver indícios de que o uso do chat educacional, enquanto artefato de mediação cultural possibilitou aos participantes a verbalização/explicitação de entendimentos sobre o papel do professor. Apesar de tal característica não se evidenciar como uma atividade reflexiva em si, ela pode indicar movimentos sócio-cognitivos de tomada de consciência e (re)elaboração das significações trazidas pelo alunos-professores a partir do contato com o outro (outrem)

Se retomarmos o conceito de reflexão como atividade situada possibilitada pelo engajamento de indivíduos em comunidades discursivas das quais não participavam, podemos afirmar que o uso do gênero digital chat educacional se configura, nessa primeira interação, como um espaço onde novas posições podem ser assumidas pelos alunos-professores, ao mesmo tempo, em que lhes permite mobilizar significações construídas ao longo de suas trajetórias pessoais em interface com outros modos de encará-las.

No entanto, faz-se necessário analisar o papel dessas atitudes no desenrolar da intervenção realizada com o chat. Para tanto, partiremos agora para análise do último chat educacional.

\section{Análise das interações no chat educacional 5}

A última interação via chat contou com a participação de oito alunos-professores e a mediação do P1, sendo quatro alunos da U1 e quatro alunos da U2. O número total de interações de cada aluno está representado na Figura 2.

É possível perceber que, nessa última interação, houve um maior número de turnos por parte dos participantes. O número de turnos é praticamente o dobro da primeira interação. Tal aspecto pode ser explicado pela intervenção realizada com os alunos-professores para o aprendizado do gênero assim como a própria familiarização destes com a ferramenta. 


\section{Interações}

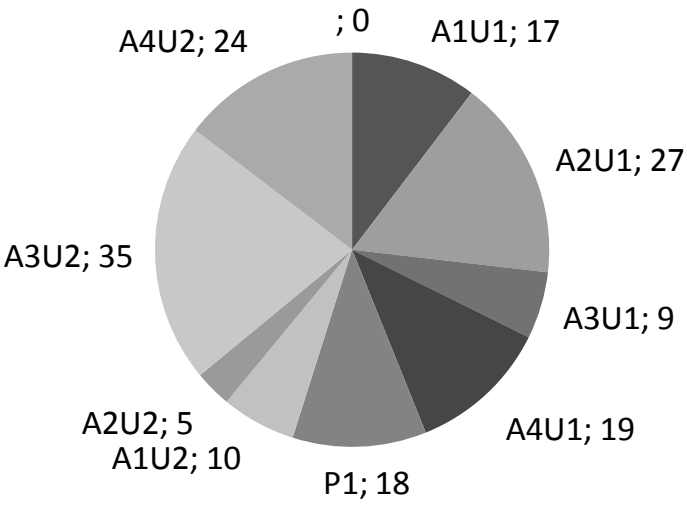

Figura 2 - Número de interações do último chat

No excerto 3, apresentamos um exemplo da articulação do tópico de outros chats educacionais com esse último, e a incitação de um dos alunos-professores aos demais de como encarar os desafios de ensinar numa concepção em que não se transmite conhecimento.

\section{Excerto 3}

A3U1: we have the opportunity to change something if we want A3U2: I agree with A4U1

A4U2: thinks in the group....

A2U1: Doubtless, this task of helping them create the knowledge by themselves is no easy task

A2U1: But it is worth it

A3U2: we shouldn't just share knowledge, I have to build it

A3U2: we*

A4U1: we have to build it but also give them the tool to do that

A3U2: but you guys already said this

A2U1: Yes

A3U2: this is our challenge

A4U1: I agree that it's hard A2U1...

Essa discussão foi gerada a partir de um texto acadêmico que explanava sobre o papel das novas tecnologias no ensino de línguas 
“But, don't you think...?”: chat educacional...

estrangeiras. Dada essa provocação, os alunos-professores, ao se projetarem enquanto profissionais da área, relatam sua inquietude em mudar de um paradigma de transmissão de conhecimento para construção de conhecimento coletivo. Nesse momento, apesar de verem isso como desafio, os alunos-professores não mostram indícios de atitude reflexiva quanto às práticas pedagógicas alternativas, como a que eles estão vivenciando.Os alunos-professores não articulam reflexivamente a participação deles no chat educacional como uma possibilidade de construção coletiva de conhecimento e que poderiam a levar novas práticas escolares. Analogamente, os professores moderadores também não instigam essa atitude reflexiva por meio de questionamentos ou chamando atenção dos alunos-professores para a prática de linguagem que vivenciam no momento como uma possibilidade de reflexão.

O exemplo 4, a seguir, ilustra representações dos alunosprofessores acerca de professores em serviço. A temática surgiu a partir da discussão da necessidade de usar recursos tecnológicos nas próprias práticas pedagógicas.

\section{Excerto 4}

A2U1: But usually teachers after graduation don't continue their studies if they'll teach at state schools]

A1U1: It is true A2U1

P1: I see your point A3U2, but I don't think just desire to learn from a teacher is enough for him/her to be updated... do you think that's enough?

A3U2: well, I learned all I know alone... all the children do it

A3U1: it is not enough P1...

A4U2: really, teachers needs to want this, but is necessary to know that this is important for him/her and for the people

P1: Alone? so, we don't need teacher... do we?

A4U1: yeah A2U1... they do not see the necessity for that if they keep teaching in public schools

A3U1: they do not have time, patience in many times for this

A4U2: to know*

A3U2: it's not complicated, P1. I agree that alone is harder

É importante ressaltar que as representações construídas pelos alunos-professores, nesse momento da interação, são baseadas no senso comum sobre o trabalho docente da rede pública de ensino. São representações que legitimam o individualismo e a responsabilização 
do professor pelos problemas educacionais ao invés de articulá-las a questões sociais, culturais e econômicas que levam o professor da escola pública a dispor de pouco tempo para se engajar em atividades de formação continuada. O papel do mediador mostra-se relevante nesse contexto já que é ele quem tenta problematizar as representações dos alunos-professores. No entanto, as experiências prévias dos alunos-professores parecem permanecer mais fortes, conforme já apontado por estudos como o de Gimenez (1998). O participante A3U2, por exemplo, afirma "well, I learned all I know alone... all the children do it”. A visão do participante é a de que, assim como sua experiência anterior ao curso de Letras parece sugerir, a aprendizagem acontece de forma unicamente cognitiva e individualista. Os aspectos sociais e interacionais envolvidos na aprendizagem são desconsiderados pelo participante nesse excerto.

Nesse excerto, não há indícios de atitude reflexiva por parte dos alunos-professores. Eles criticam os profissionais em serviço, mas não vão avante à tentativa de solucionar o problema ou, pelo menos, de apresentar propostas alternativas. Ainda,não problematizam o papel das estruturas macro e micro da sociedade na constituição do 'professor que não deseja estudar após a graduação'.

O excerto 5 traz uma discussão pontual sobre um tópico do texto em debate. Um dos alunos-professores levanta a questão sobre o entendimento dos demais acerca do que a expressão esquizofrenia cultural significa e engatilha a discussão. Os alunos-professores, então, apresentam diversas tentativas de construção da definição do que o autor do texto fonte quis dizer com a referida expressão.

\section{Excerto 5}

A2U1 : He said something that called my attention: (...)

A2U1: "O desafio do professor é achar o ponto equilíbrio entre a preservação da nossa individualidade e a aceitação da diversidade do outro, evitando uma espécie de ESQUIZOFRENIA CULTURAL" (...)

A2U1: What did he mean by this "cultural esquizophreny"? (...)

A3U2: as Leffa said the teacher needs competence and attitude

A4U1: well, because students must preserve their identities!!! We are not asking them to lose it or to put it aside in order to acquire another culture or 
“But, don't you think...?”: chat educacional...

identity.

A3U2: some teachers have competence, but they don't have attitude, and some has attitude but doesnt have competence.

A1U1: but I think what he meant was that we have to know how to embrace the two things otherwise you'll go nuts..

A4U1: we're just giving them tools to express themselves and what they are and believe

A4U2: the teacher needs want to broke the paradigms

A4U2: your paradigms

A4U2: break*

A3U2: our responsibility as teachers to-be is to have competence and attitude

No exemplo acima percebemos, novamente, a implicação dos alunos-professores nas posições por eles assumidas, por meio de uso dos dêiticos pessoais $W e$, our and $I$. Além disso, o papel da teoria na interface com a prática fica em evidência, como defendido por Pimenta (2002). Os alunos-professores travam um embate na busca de significados pelo termo esquizofrenia cultural, apresentando ideias diferentes na busca pela adesão dos demais participantes. O importante nessa parte é o indício de que o engajamento deles na comunidade profissional da qual participam parece favorecer a atitudes reflexivas, conforme demonstra o exemplo. Os alunos-professores se engajam em um diálogo para entender o significado da expressão esquizofrenia cultural e se revezam na tomada de turnos expressando suas opiniões. O participante A1U1, por exemplo, depois de alguns turnos que os demais alunos-professores explicitam suas posições, interroga a visão de seus colegas (but I think that what he meant...”) e apresenta sua própria versão.

Os dados sugerem que tal procedimento de interação criou condiçõespara uma progressão linguística, cognitiva e subjetiva, uma vez que os participantes envolvidos sentiam a necessidade de melhora linguística para expor suas ideias coerentemente, além de trazerem para este espaço de interação suas experiências de vida e acadêmica. No entanto, tais condições podem ou não terem sido sustentadas mais continuamente depois da participação dos alunos-professores no chat.

Ainda nesse sentido, pode ser evidenciado pela análise empreendida que o chat educacional não se configurou como um lócus privilegiado de engajamento dos alunos-professores em atitudes reflexivas, mas aponta para potencialidades do uso de chat 
educacionais em futuras investigações. A apropriação do artefato simbólico pelos alunos-professores possibilitou-lhes novas oportunidades de se inserir na comunidade profissional da qual começam a participar.

Ao mesmo tempo, tal apropriação sugere que o espaço criado ampliou novos modos de agir e dizer desses alunos-professores e colocou-os em confronto com suas próprias significações sobre quem são enquanto profissionais. Apesar de tal característica não ser suficiente para indicar o desenvolvimento de atitudes reflexivas, ela pode desempenhar um papel importante na propulsão de questionamentos das práticas sociais e educativas.

\section{Considerações finais}

Por entender que a formação de professores de línguas precisa ser orientada por uma concepção de tornar o aluno-professor agente da sua própria prática e capaz de se reconhecer como membro da comunidade profissional na qual deseja ingressar, optamos por analisar o papel de chats educacionais como ferramentas para o engajamento em atividades de reflexão situada.

Conforme apontado na análise, as interações ocorridas por meio do chat educacional foram propiciadoras de atitudes reflexivas em alguns momentos. As características inerentes ao gênero digital chat educacional - como por exemplo, sincronia, verbalização escrita daquilo que pensamos e produção colaborativa - parecem ser potencializadoras para (re)elaboração das compreensões que construímos do/no mundo.

O uso do gênero chat educacional como instrumento para reflexão pode ser adequado a situações em que o aluno-professor tenha sua voz ouvida, enquanto agentes de sua própria história, e pode quebrar padrões de assimetria entre professor e aluno-professor. No entanto, nem todos os momentos se configuram como propícios à reflexão. Acreditamos, pois, que uma das limitações deste estudo refere-se ao papel de mediação do professor, uma vez que este poderia ter sido melhor exercido, assim como a utilização de outros textos fontes para fomentar as discussões. 
"But, don't you think...?": chat educacional...

Ainda, faz-se necessário ressaltar a necessidade de problematizar o uso de novas tecnologias na formação de professores bem como as suas vantagens e/ou desvantagens. $\mathrm{O}$ uso do chat como ferramenta para promoção de reflexão foi propiciado graças a instalações físicas adequadas e necessidade criada por meio da aprendizagem do gênero. No entanto, pouco se questiona acerca do papel que tal intervenção pode ter na formação dos alunos-professores. Uma meta-análise do uso do chat educacional em sua própria formação poderia resultar em novas compreensões por parte dos alunos-professores assim como dos próprios professores formadores.

\section{Referências}

BRONCKART, Jean-Paul. Atividade de linguagem, textos e discursos: por um interacionismo sócio-discursivo. São Paulo: EDUC. Tradução de Anna Rachel Machado e Péricles Cunha, 2003.

. Atividade de linguagem, discurso e desenvolvimento humano. Campinas: Mercado de Letras, 2006.

. O Agir nos Discursos: das concepções teóricas às concepções dos trabalhadores. Tradução de Anna Rachel Machado e Maria de Lourdes Meirelles Matêncio. Campinas: Mercado de Letras, 2008.

CONTRERAS, José. Contradições e contrariedades: do profissional reflexivo ao intelectual crítica. In: —_. A autonomia de professores. São Paulo: Cortez, 2002, p. 133-186.

CRISTOVÃO, Vera L.L.Gêneros textuais e educação inicial do professor de língua inglesa. Linguagemem (Dis)curso, Palhoça, v.10, n.3, p. 705-734, 2010.

FLENDER, Lynn. Teacher reflection in a Hall of Mirrors: historical influences and political reverberations. Educational Researcher, v.32, n.3, p. 16-25, 2003. 
GERALDINI, Alexandra F.S. Chat educacional: que espaço é esse? Signum, v. 8/1, p. 39-70, 2005.

GIMENEZ, Telma. Language learning and language teaching: socialization and education in 'Letras' courses. Revista da Área de Humanas-Boletim CLCH, n.35, p. 35-42,1998.

- Desafios contemporâneos na formação de professores de línguas: contribuiçõos da linguística aplicada. In: FREIRE, Maximina M.; ABRAHÃO, Maria H.V.; BARCELOS, Ana M.F. (Org.). Linguística Aplicada e Contemporaneidade. São Paulo: ALAB,2005, p. 183-201.

GIROUX, Henry A.Professores como Intelectuais: ruma a uma pedagogia crítica da aprendizagem. Porto Alegre: Artmed,Tradução Daniel Bueno, 1997.

HILGERT, José G. A construção do texto falado por escrito: a conversação na internet. In: PRETI, Dino. (Org.). Fala e Escrita em questão. São Paulo: Humanitas, FFLCH/USP, 2000.

LAVE, Jean; WENGER, Etienne.Situated learning: legitimate peripheral participation. Cambridge: Cambridge University Press, 1991.

MARCUSCHI, Luiz A. Gêneros textuais emergentes no contexto da tecnologia digital. In: MARCUSCHI, Luiz A.; XAVIER, Antônio C. (Org.). Hipertexto e gêneros digitais. Rio de Janeiro: Lucerna, 2004, p. 13-90.

MATENCIO, Maria L.M. Gêneros Discursivos na Formação de Professores: reflexões sobre a construção de saberes e o processo de letramento. In: GIL, Gloria; VIEIRA-ABRAHÃO, Maria H. (Org.).Educação de Professores de Línguas: os desafios do formador. Campinas: Pontes Editores, 2008, p. 189-199. 
“But, don't you think...?”: chat educacional...

OVENS, Alan; TINNING,Richard.Reflection as situated practice: a memory-work study of lived experience in teacher education. Teaching and teacher education, v. 25, p.1125-1131, 2009.

PIMENTA, Selma G.Professor reflexivo: construindo uma crítica. In: PIMENTA, Selma G.; GHEDIN, Evandro. (Org.). Professor Reflexivo no Brasil - gênese e crítica de um conceito. São Paulo: Cortez, 2002,p. $17-52$.

SCHON, Donald .A. Using a reflective teaching to develop professional skills. In:__. Educating the reflective practioner. Londres: Jossey-Bass, 1987, p. 157-172.

ZEICHNER, Kenneth .M.Research on teacher thinking and different views of reflective practice in teaching and teacher education. In: CARLGREN, Ingrid; HANDAL, Gunnar; VAAGE, Sveinung. (Ed.). Teachers' minds and actions: research on teachers' thinking and practice. London: Falmer Press, 1994, p. 9-27.

WENGER, Etienne. Communities of supportive professionals. Alexandria, TESOL, 2005.

VIGOTSKI, Lev.S.Pensamento e Linguagem. São Paulo: Martins Fontes, 2a . ed. Tradução de Jefferson Luiz Camargo, 1998.

\section{Apêndice}

\section{Excerto 1 - Tradução}

A1U1: aquele vídeo representa tudo o que eu tenho dito ao longo dos anos...nós podemos mudar o mundo pela educação...mas nós temos que mudar e aceitar que esse é nosso trabalho.

A3U2: eu concordo. Nós encontramos um monte de soluções para outros problemas, mas para coisas importantes, nós simplesmente esperamos que as coisas melhorem

P2: governo, desculpa

A2U1: precisamos de dinheiro

A1P2: o poder da comunicação é forte, mas precisamos de suporte para 
ideia

A2U1: precisamos de vontade política, como a Eliane disse.

\section{Excerto 2 - Tradução}

A2U1: mas quem é esse "todo mundo"?

A2U2: nós precisamos de muitas coisas para chegar lá, não podemos [ficar] desmotivados.

$\boldsymbol{E} \boldsymbol{U}$ : pessoas também.

A2U1: professores, alunos, governos, familia .... a sociedade como um todo. [...]

A2U1: nós não podemos ficar desmotivados... essa é a verdade senão, nada vai acontecer.

A1U2: dinheiro é o problema, o professor é a solução.

A3U2: todo mundo tem o poder de mudar, inclusive com o voto.

A2U1: rsrs, você tá certo, A3U2, mas infelizmente o voto é o que me desmotiva mais.

A1U1: Gente...são 5 milhões de crianças....como nós podemos mudar esse cenário se as pessoas não fizerem nada...é isso que o vídeo está tentando mostrar... as ideias mais loucas podem se tornar as melhores...nós precisamos continuar trabalhando arduamente.

\section{Excerto 3 - Tradução}

A3U1: nós temos a oportunidade de mudar algo se quisermos.

A3U2: Eu concordo com A4U1

A4U2: pensar em grupo....

A2U1: Sem dúvidas, a tarefa de ajudá-los [os alunos] a produzir conhecimento por si só não é fácil.

A2U1: mas vale a pena.

A3U2: nós não deveríamos só compartilhar conhecimento, eu tenho que construir também.

A3U2: nós*

A4U1: nós temos que construir mas também dar as ferramentas para eles fazerem isso.

A3U2: mas vocês já disseram isso

A2U1: $\operatorname{sim}$

A3U2: esse é nosso desafio

A4U1: eu concordo que seja difícil, A2U1... 
"But, don't you think...?”: chat educacional...

\section{Excerto 4 - Tradução}

A2U1: Mas geralmente os professores depois da graduação não continuam seus estudos se eles ensinam em escolas públicas.

A1U1: é verdade, A2U1

P1: Eu entendo seu ponto de vista, A3U2, mas eu não acho que o simples desejo de aprender por parte de um professor é suficiente para elelela se atualizar....você acha que é suficiente?

A3U2: bem, eu aprendi tudo o que eu sei sozinho...todas as crianças aprendem.

A3U1: não é suficiente P1...

A4U2: realmente, os professores têm que querer isso, mas é necessário saber que isso é importante para ele/ela e para as pessoas.

P1: Sozinho? Então, nós não precisamos de professores ....precisamos?

A4U1: sim A2U1... eles não vem a necessidade disso se eles continuam ensinando na escola pública.

A3U1: eles não têm tempo, paciência muitas vezes para isso.

A4U2: saber* $^{*}$

A3U2: não é complicado, P1. Eu concordo que sozinho é mais difícil.

\section{Excerto 5 - Tradução}

A2U1 : Ele disse algo que chamou minha atenção:

(...)

A2U1: "O desafio do professor é achar o ponto equilíbrio entre a preservação da nossa individualidade e a aceitação da diversidade do outro, evitando uma espécie de ESQUIZOFRENIA CULTURAL"

(...)

A2U1: O que ele quis dizer com "esquizofrenia cultural"? (...)

A3U2: como o Leffa disse os professores precisam de competência e atitude. A4U1: olha, porque os alunos precisam preservar as identidades deles!!! Nós não vamos pedir a eles para descartar ou colocar de lado para que possam adquirir outra cultura ou identidade.

A3U2: alguns professores têm competência, mas eles não tem atitude, e alguns tem atitude mas não tem competência.

A1U1: mas eu acho que o que ele quis dizer foi que nós temos que saber como abraçar ambas as coisas, senão ficaremos loucos.

A4U1: nós simples estamos dando a eles ferramentas para eles se expressarem o que são e no que acreditam.

A4U2: o professor precise querer quebrou os paradigmas.

A4U2: seus paradigmas*

A4U2: quebrar* 
Lucas M. Anjos-Santos; Eliane S. Rios-Registro

A3U2: nossa responsabilidade como futuros professores é ter competência e atitude.

Submetido em: 15/10/2013

Aceito em: 24/10/2014

Title: “But, don't you think...?": educational chat for reflection in preservice English teacher education 